\title{
First Aid for a Mummy Cover of Colored Cartonage with a Detailed Study of Its Components -Late Age- Saqqara, Egypt
}

\author{
Naglaa M.Ali \\ Conservation Department, Faculty of Archaeology, Faiyoum University, Egypt
}

\begin{abstract}
The first aid has been applied on a mummy cover of colored cartonnage, with a detailed study of its components. The cover was found in Saqqara area, belongs back to the Late Age, and has been stored in Saqqara warehouses since 2010.The first aid is represented in mechanical cleaning and initial sterilization using transparent ethyl alcohol, as well as making a new holder for initial conservation of the Mummy cartonnage cover until conducting the final restoration processes. The study of the mummy cartonnage cover components was applied using optical microscope and electron microscope with an analysis unit EDX. Through the study it was found that the fabric used is linen, besides, there is fungal damage represented in the presence of fungus Asperagullus and Pincillum, beside that the cover suffers from the presence of many aspects of damage, such as cracks, holes and fragile structure. By means of the analysis with scanning electron microscope, there were certain elements, (gold, silver, aluminum, calcium, copper, magnesium, sodium, mercury, silica, iron, oxygen and sulfur) and through analysis with X-rays diffraction, it was apparent the presence of the mineral of calcite, as an essential compound for the ground of preparation, and vermilion (cinnabar mineral), as a red pigment, and Egyptian blue as a blue pigment . The bonding material of pigments was the animal glue.
\end{abstract}

\section{Introduction}

The first aid process is necessary and very important for the antiquities, specially, the organic ones; suffering from critical problems when extracted from the burial environment, due to the possibility of its total collapse if there is no rapid intervention processes by the first aid restoration. The researchtopic is a first aid restoration of a mummy cartonnage cover of $175 \mathrm{~cm}$ in of length, and width with different dimensionsin accordance with the shape of the cover. The cover was discovered in Saqqara area,2010 and belongs to the Late Age (395-332 BC), and is decorated with various motifs represented in: a drawing of a wig at the head area, adorned with a drawing of deceased ideal features, most likely of a woman. The chest area is adorned with the usual Pharahonic necklace. Whereas the area next to the chest, there is a view of a goddess wearing a double horned crown with the disk of the sun in between, and spreading her wings for protection. There under, a view of the process of mummification performed by the god Anubis for the mummy lying on the mummification bed, and underneath the bed, the scene of the four Canopic stock pots may be seen, where the bowels of the deceased may be placed in on mummification, carrying the heads of the four sons of Horus, namely; "Amsty, Hapi Dwamut F, Quabeh Snow F". This is a decorative view of a decorative symbols associated with Osier and Isis, and at the bottom we find the view of goddess Nekhbet, spreading her wings for protection, and then the view of the eastern and the western horizon in the form of hawk's head, and there above the disk of the sun.(Lesko,L,H.2001) The Cover suffers from extreme weakness, and cracking at many parts thereof, as well as the development of some fungi on the fabric layer, represented in fungi (Asperagullus and Pincillum ) The first aid restoration processes were represented in covering the mummy with polyethylene to isolate it from interaction with the external environment. Following that, the mechanical cleaning, initial sterilization with ethyl alcohol to stop temporarily the fungi activity and making a new holder of the cartonnage to preserve it until performing the final consolidation process after the final restoration (Acton,K. 2012).

Through the detailed study of the mummy cover components, it is found that the cover is made of three layers (Helmi,F.2015): the first is the holder layer, from linen, the second is the layer of the depiction ground, from calcium carbonate (calcite) mixed with a small amount of gypsum, whereas the layer of Pigments, has included (the Egyptian blue, Gold, cinnbar, calcite and a proportion of hematite).

\subsection{Materials}

\section{Materials and Methods}

The use of certain materials necessary in the first aid process, represented in using ethyl alcohol in the initial sterilization of the mummy and the cartonnage cover, especially from the back, as it is the part adjacent directly to infected mummy, flexible polyethylene sheets, to cover the mummy and isolate the new holder from pure gypsum, and also pure gypsum was used in casting the new holder for the protection of the fragile cartonnage cover against total disintegration) 


\subsection{Methods of inspection}

\subsubsection{Visual inspection}

Visual inspection was used to identify the problem present on the mummy cartonnage cover, visible to the naked eye, such as cracks areas, desquamation, missing parts, separate layers from each other, fungi spots, distorting the antiquity, as well as crystalline salts. After a full visual inspection of the colored cartonnage cover, very small samples have been taken from the dilapidated parts of (the fabric, ground layer, and pigments), as shown in Figure (1).

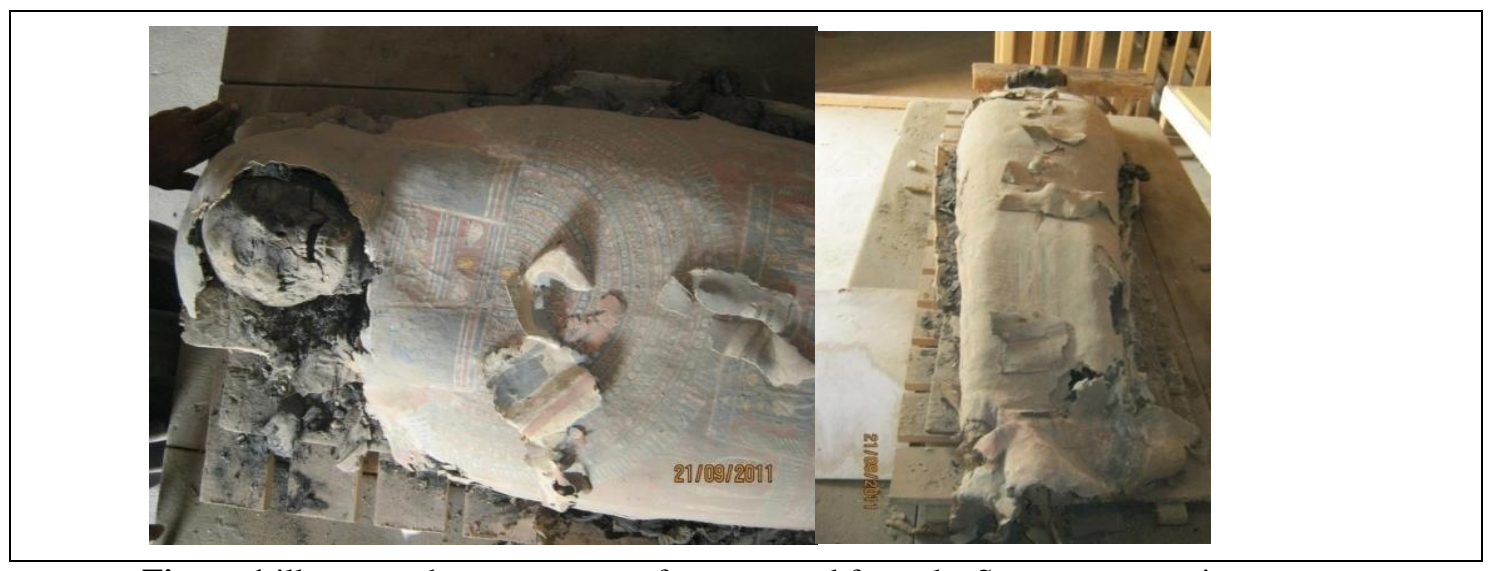

Figure 1 illustrates the cartonnage after extracted from the Saqqara excavations stores

\subsubsection{Microbiological examination}

Microbial swabs were taken from spot areas on the mummy cartonnage cover back-ground, using (Swaps) to develop it in special incubators, and examine them later on, under a light microscope to identify the types of pathogenic microorganisms causing the spots distorting and destructive to the cartonnage cover.

\subsubsection{Scientific devices used in examination and analysis}

The samples taken from the colored cartonnage cover were examined and analyzed using a number of scientific instruments to see the composition of each layer and the damage inflicted thereon, where the examination instruments have been used to see the most important and the most accurate manifestation of damage, and then the analysis devices to identify the elemental composition of each item separately, as well as the most important compounds of the cartonnage cover, and the most important damage compounds on the colored cover. These devices are:

\subsubsection{Examination using a light microscope}

The light microscope was used to identify the fabric used as a holder for the colored cartonnage cover. As well as, the light microscope was used to examine the isolated microorganisms on the colored cartonnage cover. (Ali,N.2011)

\section{2-2-3-2.Examination and analysis using a scanning electron microscope, equipped with an X-ray distracting unit (EDX)}

The scanning electron microscope was used to examine tissue samples and preparation ground layer and the pigments to clarify the variousaspects of damage, especially the infinitesimal that cannot be seen with the naked eye or by the optical microscope. That was followed with an analysis of the same sample, for the inorganic samples, using X-ray distracting unit(EDX) to analyze the elements of each layer, and identifying exotic elements that have come thereon, and caused a change in the structure and therefore damaging the antiquity. This unit does not analyze the amorphous organic elements because this device does not analyze organic samples and does not show of the organic compounds but only carbon, so that, it is not possible to identify any change or damage that had occurred to the organic compound. (Ali,N.2011)

\subsubsection{Analysis using $X$-ray diffraction (XRD)}

The analysis was made using X-ray diffraction (XRD) to identify the crystalline chemical compounds and various salts existing in layers of cartonnage, thus, identifying the transformations in the compounds from one compound to another, as a result of interaction with the environment or the soil surrounding the mummy colored cartonnagecover, and then identifying the cause of the damage found in the colored cartonnage. 


\section{2-2-3.4. Analysis using infrared (FTIR)}

Small samples of the mummy cartonnage cover were examined, particularly from the colored areas, to see the organic binder, as all the biders that were used before were of organic origin, therefore, the infrared device was used to draw a pattern of organic compounds found in the sample taken from the antiquity. (Rein, A., 2015)

\section{3-1 First aid}

\section{Results And Result Discussion}

As a result of the circumstances of the burial, the mummy cartonnag cover had suffered, that have led to the extreme weakness in addition to the accumulation of dust and dirt, and the loss of many parts of the antiquity subject to the research in the form of husks, in addition to fungal growths of Asperagullus flavous and Pinicilliums on the antiquity back thus, the first restoration was conducted as follows:

\section{3-1-1 Mechanical cleaning}

The small hander air blower was used to remove dust weakly adhered to the colored cartonnage cover surface as shown in figure (2), and also soft brushes were also used in different sizes to remove dust and mud dirt stronger adhered to the surface of the antiquity, but doing so with extreme caution so as the vulnerable, and severely weak parts do not fall of the antiquity.

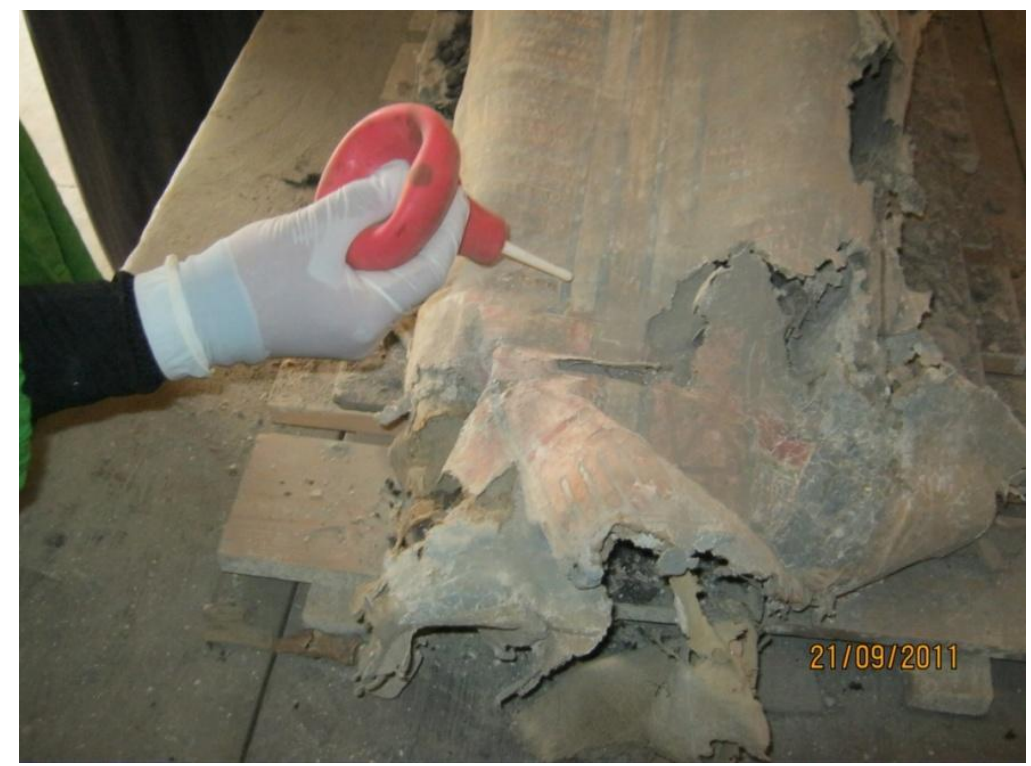

Fig.(2) describes the use of the hander air blower in the first mechanical cleaning

\section{3-1-2 Initial sterilization}

Through tests and analyzes, it was apparent the presence of fungal developments, caused by the colored cartonnagecover being in contact with the mummy, so,the colored cartonnage cover was separated from the mummy, as shown in Exhibition (2).

Ethyl alcohol was used in the process ofinitial sterilization for the cartonnage cover, as a result of its sterile properties, acting to kill a large portion of the fungus and halt the activity of the remaining part for a while (until the final restoration of the colored cartonnage)

\section{3-1-3. Makingof a new holder for the mummy colored cartonnage cover}

As a result of the state of extreme weakness in which the mummy colored cartonnage coverwas, it was necessary to make an alternative holder off the mummy after their separation as a result of the damage inflicted to both of them, to help in the protection of the mummy cover during the final treatment process. The stages of the making of the holder were as follows:

1.The mummy was covered completely with two layers; one of cotton fabric, and one layer of good, strong polyethylene sheet to isolate it completely from the surrounding environment, as it is shown in figure No. (3). 2.The mummy cartonnage colored cover was separated from the mummy itself in extreme caution. 


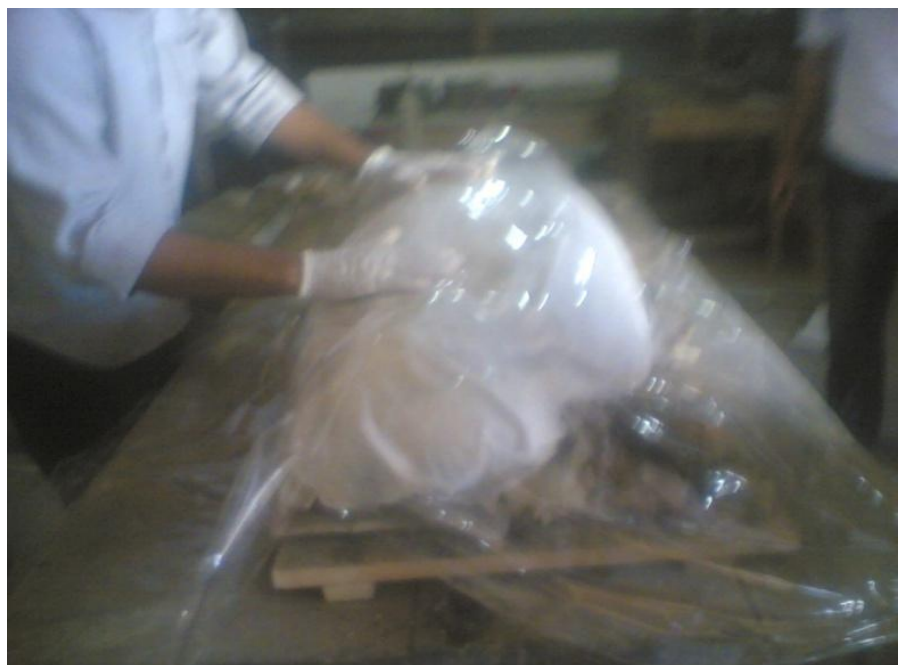

Exhibition (3) describes the full coverage of the Mummy before taking the new impression of the cartonnage new holder

3.A sheet a poly ethylene was spread on an outside table, with another sheet of gauze spread on top, saturated with pure gypsum, so to look like medical gypsum stripes used in fixing fractures, as shown in Fig. No. (4).

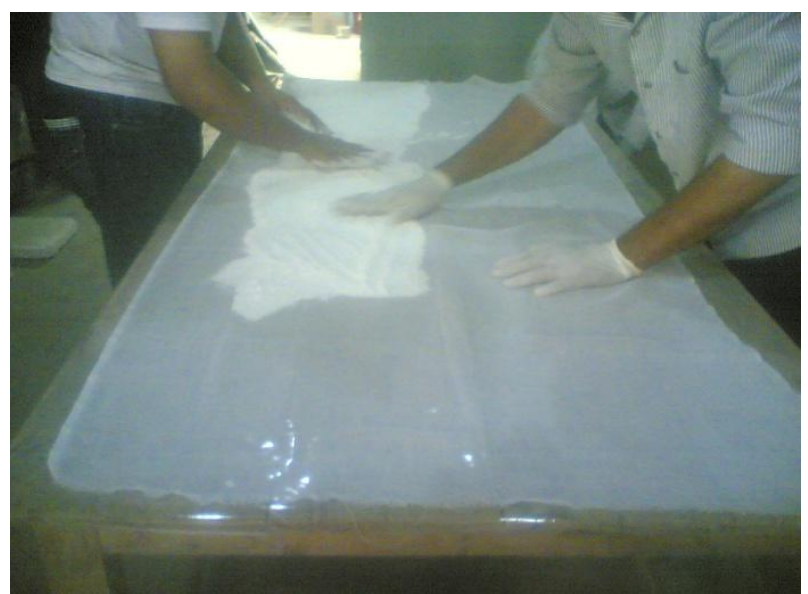

Figure (4) illustrates the process of spreading a layer of plaster and gauze on an external table

4.The polyethylene and gauze encased in plaster were quickly lifted on the Mummy covered with polyethylene to take a quick impression in resemblance of the cartonnage, that was separated as shown in Figure(5)

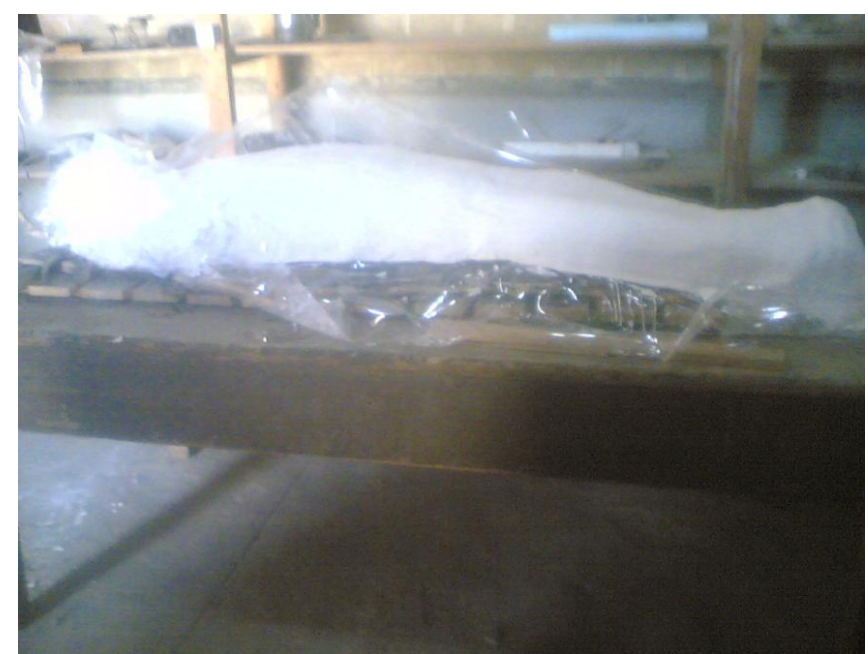

Fig. (5) illustrates the operation of taking an impression of the cartonnage holder 
5.After the drying of the pure gypsum, the last layer of polyethylene, was lifted, with its encasement of plaster away from the Mummy to complete the casting of the new holder of the Mummy colored cartonnage cover.

6.At the end, the holderof the Mummy colored cartonnage cover was placed back.

The layer of polyethylene was placed, followed by another layer of cotton fabric to protect archaeological cartonnage, and finally the cartonnage was placed inside new holder in preparation for the commencement of the final stage of treatment in the next phase, as shown in Figure (6)

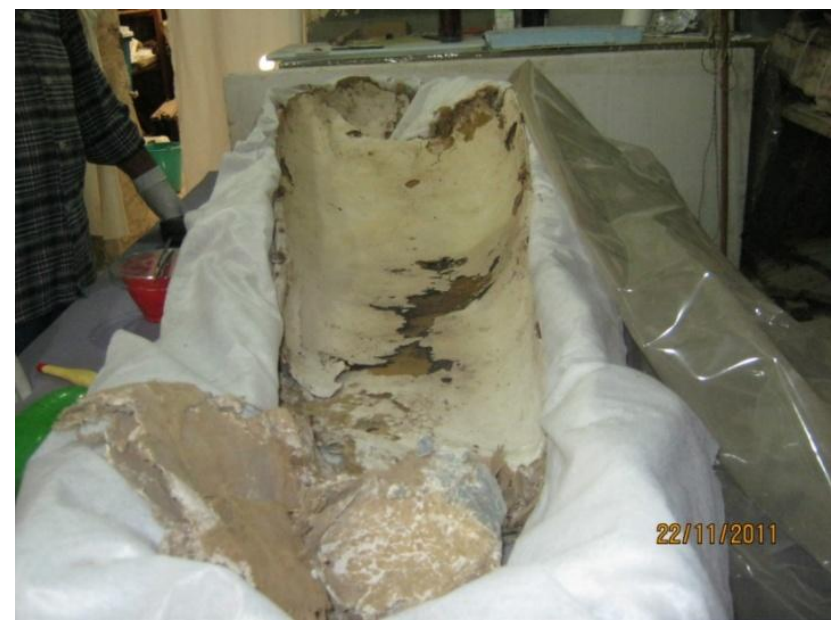

Figure (6) illustrates the new cartonnage holder after isolation with poly ethyoene and the cotton fabric, with archaeological cartonnageinside.

\section{3-2. Results of examination and analysis for the installation the mummy cartonnage colored cover}

\section{3-2-1 Results of examination using a light microscope}

It was found through examination with optical microscope that the fabric used as a holder in the mummy cartonnage colored cover is linen textile, which was revered by the ancient Egyptians, and use it for all Funerary purposes, especially in the tomb, as shown in Figure (7). The presence of linen under the ground layer and the pigment is the root cause of the survival of the complete structure of the mummy cartonnage colored covertill now. The reason in the flax textile strength and withstanding all those pressures is due to Pactine nodes strengthening and supporting the tissue.

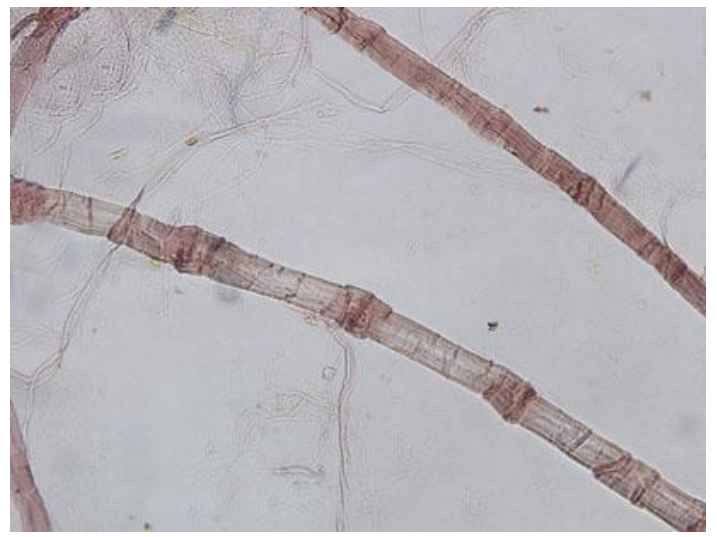

Figure 7 illustrates the linen textile under the light microscope

\section{3-2-2Microbiological test results}

After taking smears and microbiological growing on Aggar, Pottatos and Duxtrose (P.D.A). After purification of the isolates, it was proved through examination using the optical microscope, the presence of fungal growths of Asperagullus flavous shown in Figure (8), and fungus Pincillum sp. shown in Figure (9), which tarnished the mummy cartonnage colored cover. In addition to that such fungi feed on carbohydrates composing the layers of the cartonnage, and the pigments such as bonding material leading to the occurrence of cracks, peeling and separation over time. Finally, after consumption of the organic matter, these organisms feed on, the pigments turn into separate grains without link between them, thus fall in the form of powder on the ground, in evidence of the devastating effect of those organisms that live in colonies, starting as simple, but sooner turn into millions of organisms, causing destruction of the entire antiquity to generate the biological 
energy necessary to carry out its vital processes that keep it alive, and this is due to that it is unable to selfsupply power to themselves, as it is plant lacking chlorophyll thereto.

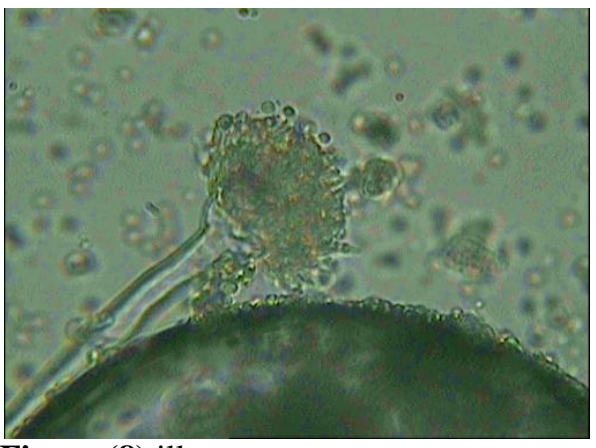

Figure (8) illustrates

Asperagullus flavous under microscope

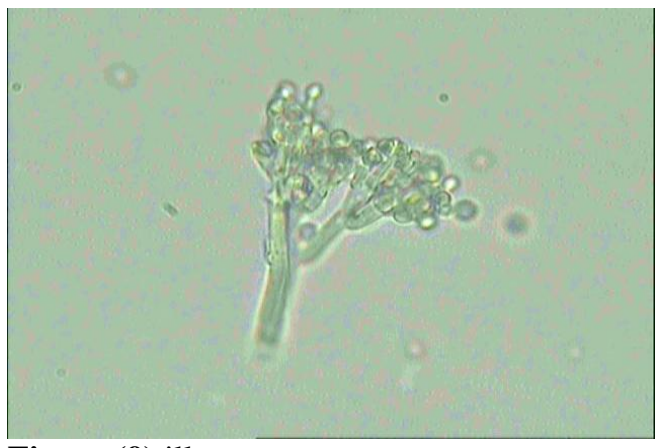

Figure (9) illustrates

pincillum sp.under microscope

\section{3-2-3 Examination using a scanning electron microscope (SEM)}

\section{3-2-3-1 linen textile examination by (SEM)}

Examination using the scanner electron microscope has shown the various manifestations of damage suffered by the mummy cartonnage colored cover, such as warp, weaknesses and corrosion resulting from fungal damage and high moisture content in the burial environment, leading to the presence of many cracks and diminishing of the linking material of the colored materials gradually, thus transferring the colored materials into powder easily fall and then the deterioration of the object, as shown in figure (10)

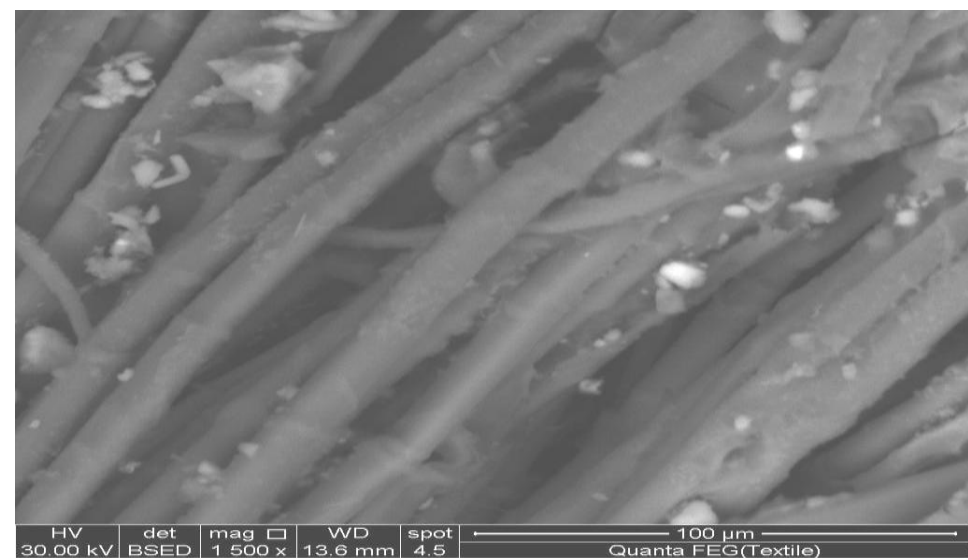

Figure (10) illustrates the scanning microscopy micrograhp of the archaeological linen fibers, where there are some salts and some spots of dirt between the fibers

\subsubsection{Examination and analysis of the mummy cartonnage colored cover ground by (SEM) and (EDX)}

Examining a sample of the mummy cover imaging ground using (SEM), it is apparent the presence of voids and gaps as a result of the fall of the parts of the ground layer and appearance of the fabric layer directly. And is likely to be a result of the sequence differing rates of expansion and contraction between the layers of cartonnage is not homogeneous in composition. The chemical and physical composition, where the cartonnage consisted of organic materials component such as a mixture composed (linen- glue) and inorganic materials such as pigments and ground layer and all of that helps to the ground loss, including pigment.

Analyzing a sample of imaging ground using unit (EDX), it was proved the existence of elements (Ca$\mathrm{C}-\mathrm{O}$ ) as components of calcium carbonate, which is the main component of the ground layer with the presence of slight ration of impurities of gypsum or it was adding to calcite to speed drying as shown by the presence of elements $(\mathrm{Ca}-\mathrm{O}-\mathrm{S})$ and probably also a sulfur content in part resulting from the transformation of calcium carbonate into calcium sulfate as a result of interaction with the element of sulfur, found within the soil or as air pollution, as shown in figure (11) The elements (Al-Si-Fe-Ca) express the presence of dust and sledge spots adherent to the Mummy cartonnage colored cover surface, where those elements are, in turn, working to speed up the rates of different damage operations, where it has been instrumental in transforming atmospheric pollution gases into acids, the object surface would absorb, and then work on the erosion of the Mummy cover surface gradually, beginning with fading of pigments on the surface of the cover, and ends with dissociation of the pigments layer and ground layer. 


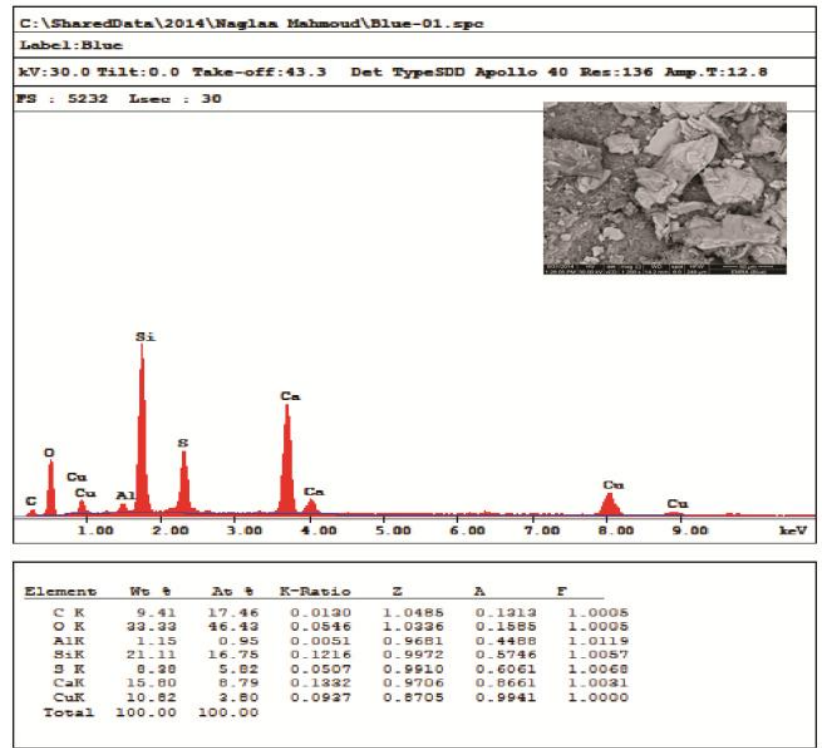

Figure (11) illustrates the micrograph and analysis of a sample of the ground layer, where there could be seen the dissociation of the compounds composing the ground

\subsubsection{Examination and analysis of the golden pigment by (SEM)}

Examining the golden substance under the scanning electron microscope, there appears that there are gaps under the microscope. Besides, having scratches on the surface, where such gaps and scratches may be resulting from an attempt to steal the gilded parts on the cover and the Mummy underneath. It can be said that the Mummy and its cover has been exposed to deliberate manmade damage intent to maim the Mummy colored cover by smashing facial features, as well as, some broken parts of the Mummy, as it is shown in the micrograph No. (12). The darker parts on the surface of the sample examined are small holes, dust and dirt adherent to the gilded layer.

It has been proven through the analysis of a sample of the gilded layer that there is gold element $(\mathrm{Au})$ by $72 \%$, and the silver element (Ag), giving the gold a certain shade of pigment and making its composition easy process. Where the elements ( $\mathrm{Al}-\mathrm{C}-\mathrm{O}$ ) indicate the presence of certain elements of soil and dust, which maim the surface of the Mummy colored cartonnage cover, and at the same time an effective role as catalysts acid interactions that take place either in the soil or occurring after the extraction of the cartonnage cover and being left in the unequipped storage, shown in figure (12)

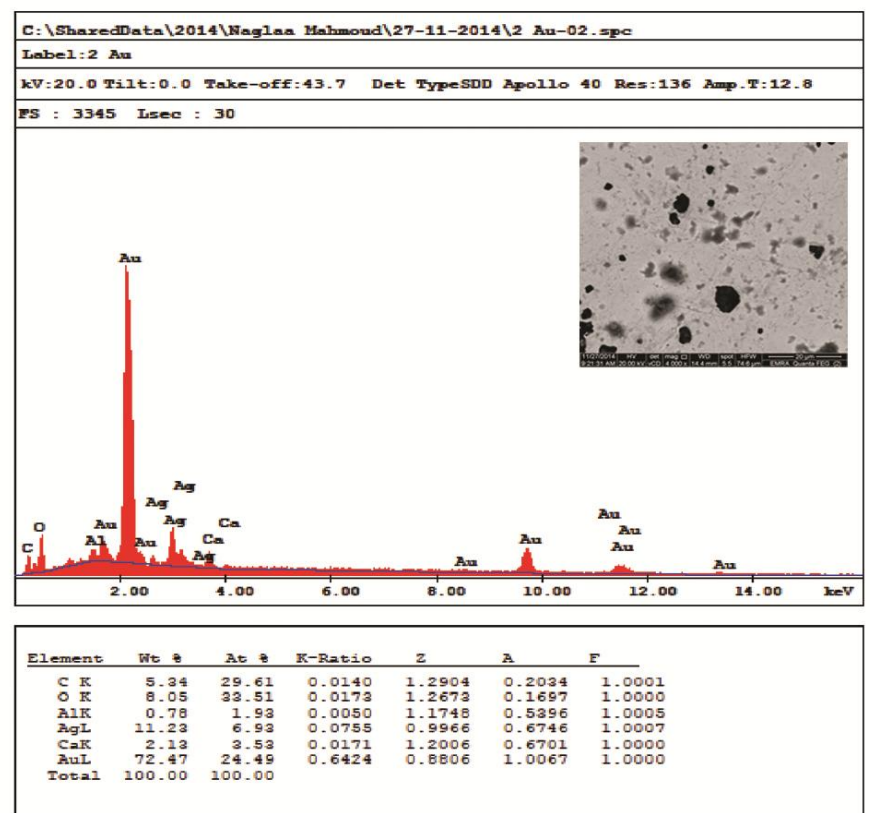

Figure (12) illustrates the examination and analysis of the gilded layer on the cartonnage surface 


\subsubsection{Examination and analysis of the red pigment using a scanning electron microscope (SEM), (EDX)}

It was found through examination of the red that there is a chromatic change in the red pigment with the presence of many cracks on the surface of the pigment as a result of the interaction of the pigment with the surrounding environment directly and in addition to the presence of a fungal growths as evidenced by microscopic examination.

By analysis of the red pigment, found that it consists of $(\mathrm{Hg}-\mathrm{S})$ and is a constituent components of red (cinnabar) vermilion, as it was found also in the same sample, elements (Ca-C- $\mathrm{O}$ ), where they are components of calcium carbonate, indicating that the ancient artist used to mix the pigment with part of ground layer, as is demonstrated by the analysis and the presence of elements (Fe-Na-Mg-CO) as elements composed of dust which distorting the object surface as well as its role in speeding up chemical reactions leading to damage.
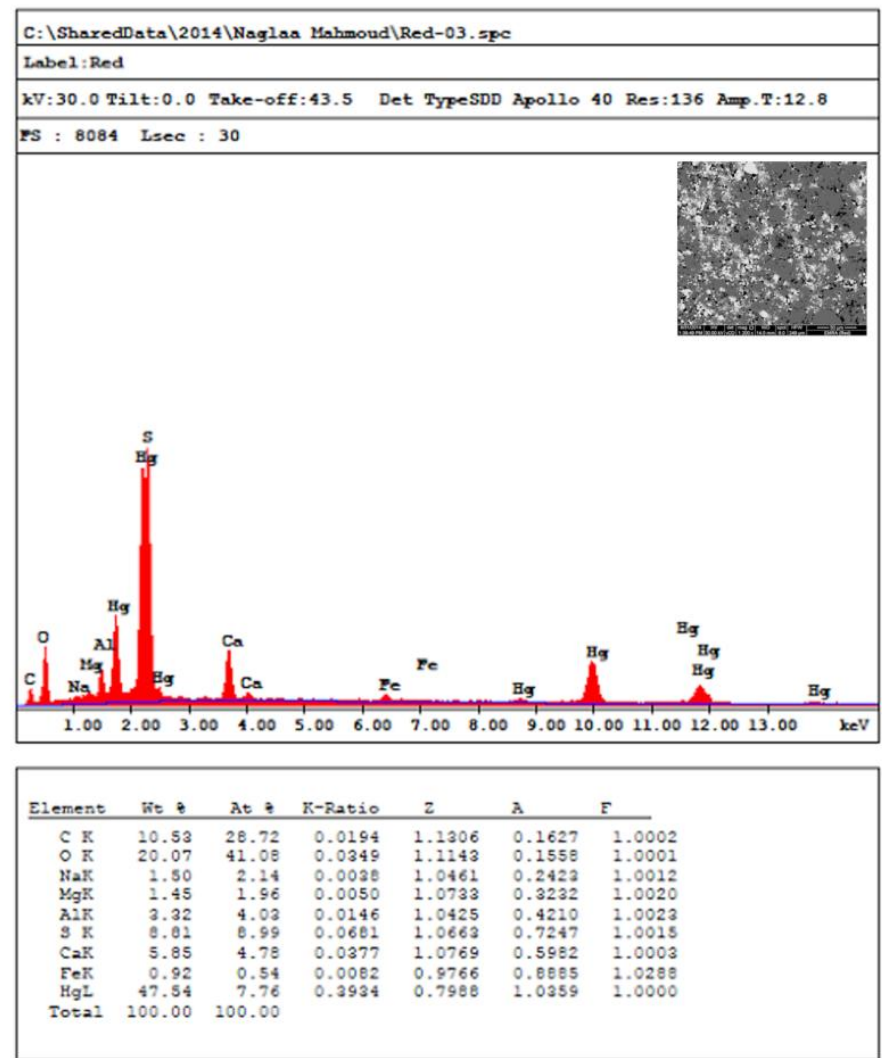

Figure (13) illustrates the examination and analysis of the red pigment, where there is obvious the blending of the vermilion with some impurities beside the dust

\subsubsection{Examination and analysis of the blue pigment using the scanning electron microscope (SEM)} EDX,)

Examining a sample of the blue pigment on the surface of the Mummy colored cartonnage cover, there appeared heterogeneity of the surface with the presence of crystals of some components of the elements of pigment and crystals of dust in addition to the unevenness of the sample surface as a result of erosion of the surface layer caused by chemical reactions in the burial environment, which led to the disintegration of the material bonding between the grains of the pigment.

By analysis of the blue pigment using the electronic scanning microscope equipped with (EDX) unit, it is obvious that the sample of the pigment contains elements ( $\mathrm{Si}-\mathrm{Al}-\mathrm{Cu}-\mathrm{Ca}-\mathrm{O})$, which are the elements 
constituent of the Egyptian blue pigment as shown in Figure (14). But the elements(C-Ca-O) illustrates the ground layer which artist mixing part of it with pigment, and finally having elemental sulfur (S), which has more than one explanation, as may be its presence as an impurity entered in lime composition, or added deliberately by the artist to speed up the process of drying of limestone material, which is used in ground layer, and finally may be due to the transformation of part of the calcium carbonate to calcium sulphate as a result of chemical reactions in the burial environment as shown in Figure (14)

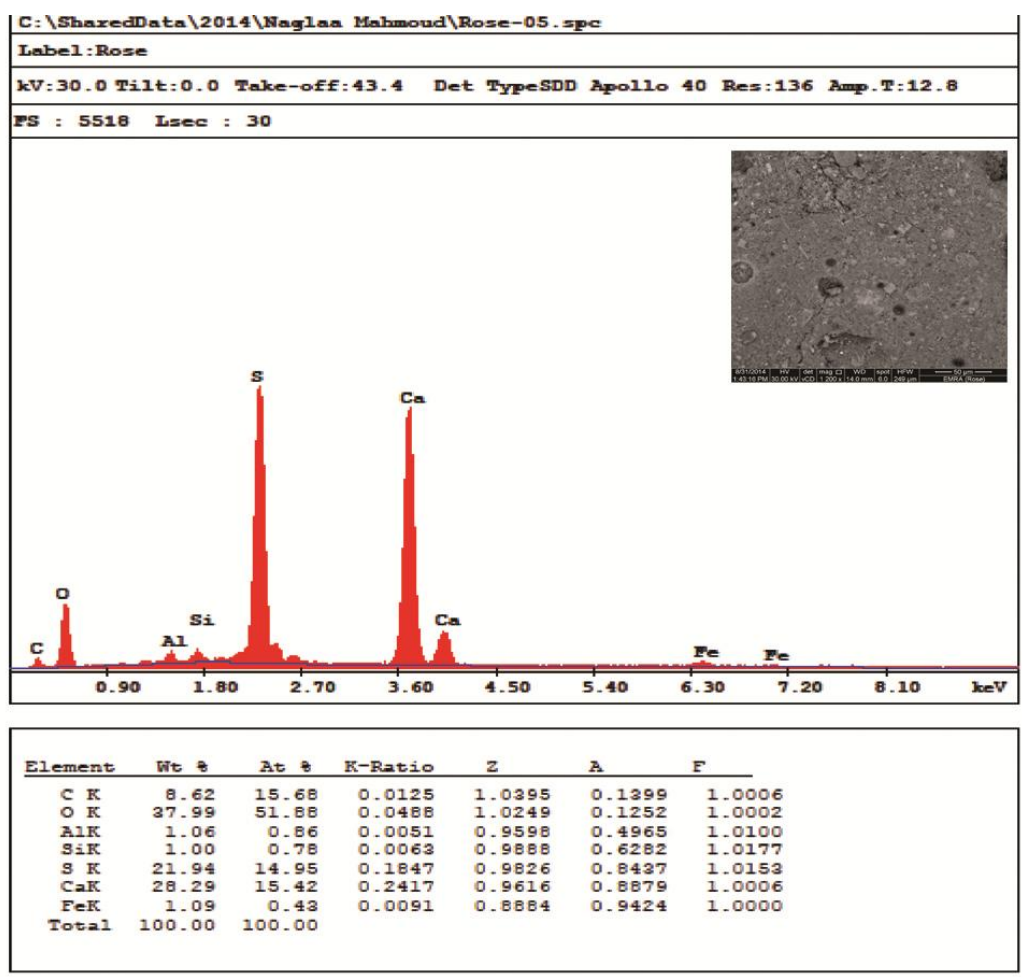

Figure (14) illustrates the examination and analysis of a sample of the blue pigment, where there are gaps and cracks on the surface of the pigment, and through analysis component forming the blue pigment elements

\subsubsection{Analysis of the golden pigment, using X-ray diffraction device:}

It was found through the analysis of a sample of pigment described in Figure (15), that the very small sample is gold Card No.(0-0784) as a golden pigment so it appears as traces in the sample. It was also found in the sample, mineral (Calcite) as a major in a small sample card No.(5-0586), which is likely to be mixed with the pigment deliberately or as part of the ground layer used by the artist when manufacturing the cartonnage, in addition to the presence of a percentage of gypsum card No.(6-0046) as an impurities. As shown in fig.15.

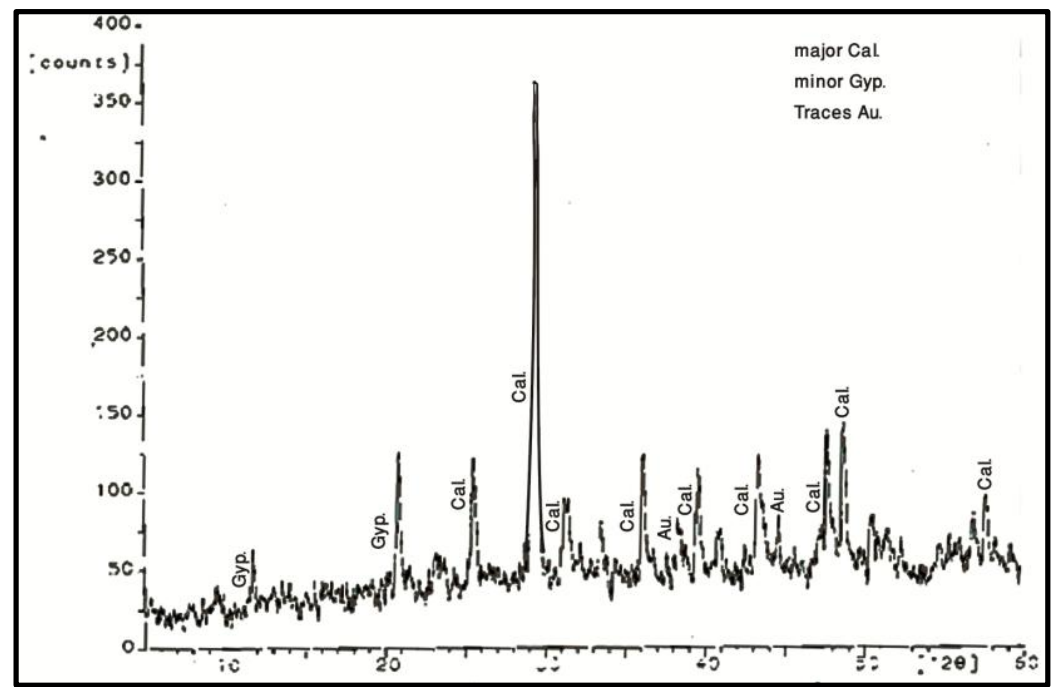

Fig. 15 Illustrates the X-Rays distraction pattern for the Golden pigment As illustrated in Fig. (16) 


\subsubsection{Analysis of the red pigment, using $X$-ray diffraction device:}

Through the analysis of a sample of red pigment Figure (16), that the sample is vermilion (cinnabar) $\mathrm{HgS}$ card No.(005-900-96) as a red pigment . It was also found in the sample cellulose $\left(\mathrm{C}_{6} \mathrm{H}_{10} \mathrm{O}_{5}\right)_{\mathrm{n}}$, as a part of textile layer this illustrates that linen still has a crystalline part which appears in XRD chart. finally presence of (Calcite) card No.( 5-0586), which is likely to be mixed with the pigment deliberately or as part of the ground layer used by the artist when manufacturing the cartonnage, in addition to the presence of gypsum card No.(6-0046) as an impurities. As shown in fig.16.

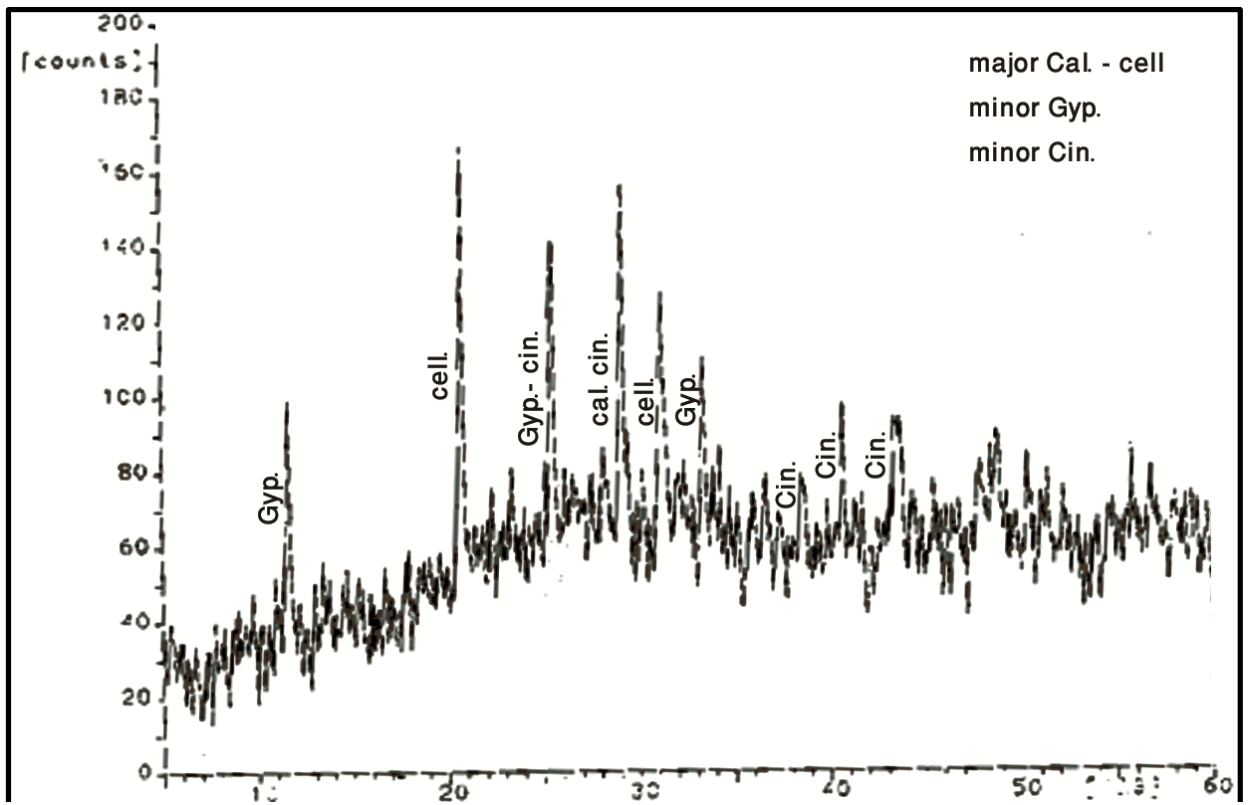

FIG. 16 Illustrates the X-rays diffraction pattern for the Red pigment

\subsubsection{Analysis of the blue pigment material, using $X$-ray diffraction device:}

It was found through the examination of a sample of blue color material described in Figure (17), that the sample matter is Egyptian blue Card No.(12-512) as a blue coloring material. It was also found in the sample, mineral (Calcite), which is likely to be mixed with the color deliberately or as part of the background of imaging used by the artist when manufacturing the cartonnage, in addition to the presence of a slight percentage of gypsum, where it may be added deliberately to calcium carbonate to speed up the drying process.

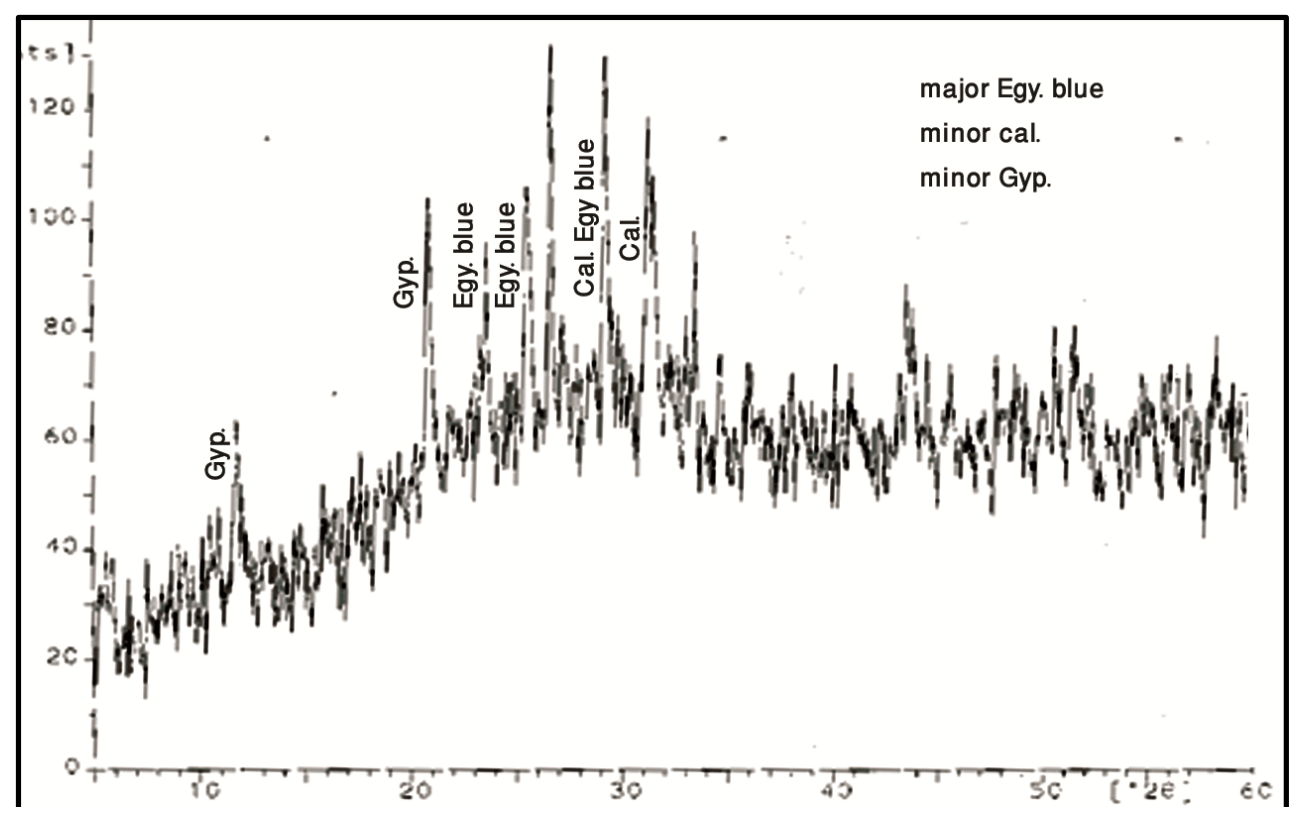

FIG. 17 Illustrates the X-rays diffraction pattern for the Blue pigment 


\subsection{Analysis of the bonding material using infrared device (FTIR)}

It had appeared through the analysis of a sample of the red pigment shown in Figure (18) that the bonding material is the animal glue (Derrick, M., 1999)

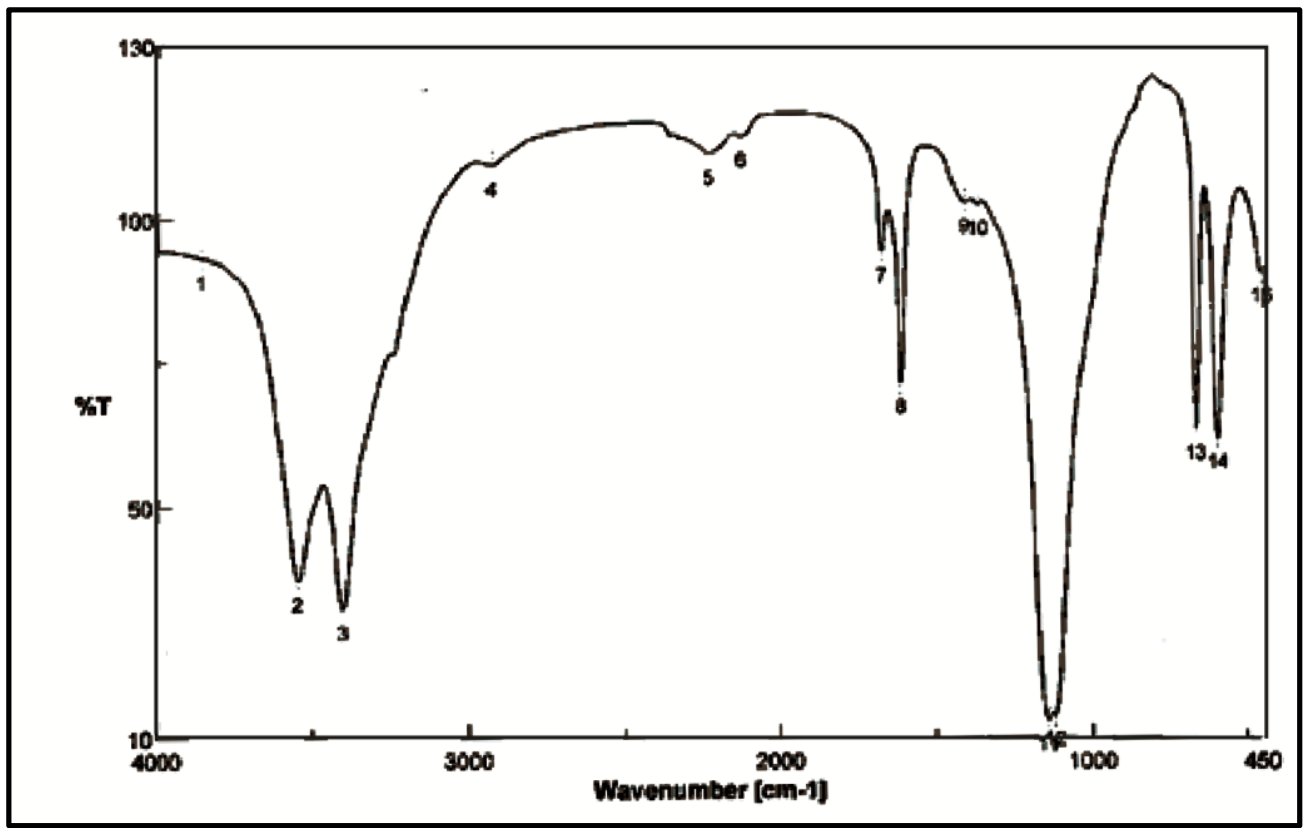

Fig. (18) Illustrates the FTIR pattern for the bonding material in red pigment (Animal glue)

\section{Conclusion}

After studying the Mummy Cartonnage Cover, the following findings were reached:

- First aid to the mummy colored cartonnage coverhelped to provide initial protection to the object until the completion of the final reinforcement process.

- Ethyl alcohol is a fast, non-destructive sterilization substance of the object, until the final sterilization using the appropriate fungicide for fungi that have been identified.

- The use of the new holder is a necessity in some cases with good insulation so as not to be a source of damage to the object, rather than protection.

- The original holder layer, which is made up of linen, which helped the relative cohesion of the object.

- in the mummy cover was calcium carbonate in addition to a percentage of calcium sulfates, which is likely to speed up the drying process, or it may be resulting from partly transformation of calcium carbonate as a result of pollution with element sulfur from the soil or air around after the disclosure.

- The golden pigment was essentially of element gold with a small percentage of silver with as demonstrated through analysis using the (EDX\& XRD) and there is a proportion of dust and dirt on the surface, including atoms of iron and aluminum

- Red pigment was a red cinnbar.

- Blue pigment was Egyptian blue.

- It is obvious from the various tests and analyzes that the artist had mixed the pigment with calcium carbonate material so as to help increase cohesion with the original ground layer.

- The artist used the animal glue medium as a scheme for the different pigment.

\section{Acknowledgement}

Finally, I present my sincere thanks and appreciation to Mr.Mustafa Abdel Fattah, director of Giza restoration administration, Ministry of Archaeology and the entire work team in the Saqqara area, for all the assistance that they have given me, and single out Mr. Ashraf Aaos. also I want to thank Prof. Dr. Ahmed Mohammed Mohamed, Plant Department, Faculty of science, Suez Canal University, and Dr. Mukhtar Mohamed Mohamed, Archaeology Department, Faculty of Archaeology, Fayoum University.

\section{References}

[1]. Aceto,M.,et.al., Thecartonnage on papyrus plasters , colors and inks excavations of museoegizio of turinat at Assiut (1905-1910), $4^{\text {th }}$ international congress on (science and technology) for the safuard of cultural heritage in the mediterraneans Basin Vol.II,Cairo ,Egypt , p.530. 
[2]. Aceto,M.,et.al., the pigments of Egyptians blue and green ,new research and analysis at the museoEglizio of torino, $4^{\text {th }}$ international congress on (science and technology) for the safuard of cultural heritage in the mediterraneans Basin Vol.II,Cairo ,Egypt ,2009, p.552.

[3]. Acton,K.,et.al.Stabilising stuff A Guide for conservaing Archaeological finds in the field .Heritage council, NSW, 2012, p.19.

[4]. Ali,N., Study of Deterioration and Degradation of Overlaid Wooden Doors in Ottoman Caravansary in Bulaq ,Cairo , Egypt EJARS,VOL.1,ISSUE.2,2011,p.34.

[5]. Amin,E.,\&Rashed,S.,Preservation and restoration of a piece of textile at the Egyptian textile museum,vol.3,ISSUE .1,2013,p.33.

[6]. Ewais,A., Study of using modern techniques in detaching wall paintings and making alternative substrates and making alternative substrates applied on the wildlife scene at the burial shaft of the tomb of Raa-Shepses in Saqqara.,phd proposal Fayoum university ,Faculty of Archaeology, conservation department, 2016 ,p.1.

[7]. Abd-El- Tawab,N.ibt, Analytical investigation of cartonnage Fragment from late period, EJARS,Vol.2,Issue.2,2012,p.69.

[8]. Chadima,S.,X-Ray diffraction and analysis of post cretaceous sand and gravel units in south estern south Dakota, California institute of technology, California,2003,P.2.

[9]. David,A., An Egyptian Cartonnge of the Graeco-Roman Period,Examination and Discoveries, Studies in conservation ,vol.48,2003,P.41.

[10]. Helmi,M.,et.al,Nanomaterials for the inhibition of microbial growth on ancent Egyptian funeral masks,M.A.A,vol.15,No.3,p.88.

[11]. Afifi,H.,Analytical investigation of pigments ground layer and midia of cartonnage fragments from greek roman period ,MAA,vol.11,No.2,p.92.

[12]. Lesko,L,H. Coffin text in Redford the Oxford Encyclopedia of Ancientgypt,vol.1.England,2001,PP.287-288.

[13]. Linington,R.,et.al.,Future directions in archaeology, Library of Congress,USA,1981,p.27.

[14]. Nicholson,p.,Ancient Egyptian materials and technology ,Cambridge,U.K.2000,pp.108,114.

[15]. Rein,A., et.al,Hand held FTIR analysis for the conservation and restoration of fine art and historical objects, Agilent Technologies,Danbury,USA,2015,PP.2,4. 